\title{
Coronavirus Disease-19 and Cardiovascular Disease
}

\author{
Irena Mitevska*, Lidija Poposka \\ University Cardiology Clinic, Skopje, Republic of Macedonia
}

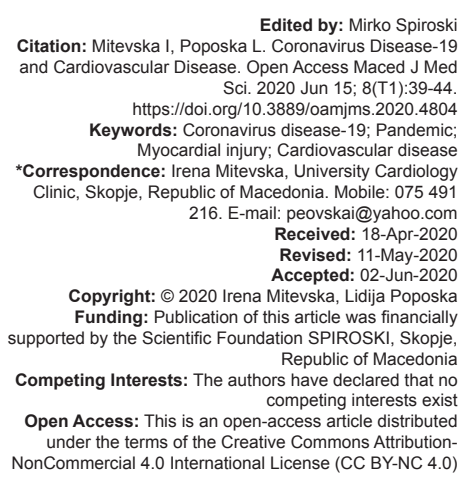

Edited by: Mirko Spirosk Edited by: Mirko Spirosk
Citation: Mitevska I, Poposka L. Coronavirus Disease-19 and Cardiovascular Disease. Open Access Maced J Med Sci. 2020 Jun 15; 8(T1):39-44
https://doi.org/10.3889/omims 2020.4804 Keywords: Coronavirus disease-19; Pandemic Myocardial injury; Cardiovascular disease
Moseas *Correspondence: Irena Mitevska, University Cardiology Clinic, Skopje, Republic of Macedonia. Mobile: 075491 216. E-mail: peovskai@yahoo.com
Received: 18-Apr-202 Revised: 11-May-2020 Accepted: 02-Jun-2020 Accepted: 02-Jun-2020
Copyright: ๑ 2020 Irena Mitevska, Lidija Poposka Funding: Publication of this article was financially supported by the Scientific Foundation SPIROSKI, Skopje, Republic of Macedonia

Competing Interests: The authors have declared that no
competing interests exis
Open Access: This is an open-access article distributed under the terms of the Creative Commons AttributionNonCommercial 4.0 International License (CC BY-NC 4.0)

\begin{abstract}
We are facing serious coronavirus disease-19 pandemic, caused by the severe acute respiratory syndrome coronavirus-2. Among infected individuals, there is a higher prevalence of the cardiovascular disease, which leads to their poor prognosis. Myocardial injury is present in more than $15 \%$ of critical ill patients in the form of acute myocardial dysfunction or subsequent myocardial injury that develops as disease severity. This new virus pandemic is a global challenge for health-care system which was we still have much to learn.
\end{abstract}

\section{Introduction}

The coronavirus disease 19 (COVID-19) pandemic has opened up several serious challenges to the world. It changed our lives in several ways. The pandemic has put enormous pressure on health-care systems worldwide. Changes in the medical system with unchanged and insufficient financial and medical resources were unexpected. Hospitals in China, Italy, Spain, and now the United States as the most affected countries have faced huge numbers of critically ill patients with COVID-19, which leads to the reduction of hospital resources, infection of medical personnel, and shortages of vital resources especially in intensive care units [1]. The experiences and numbers coming from those regions have put developing countries in the position of serious alerts and even more fear of the final health and economic impact of the COVID-19 pandemic. There are many unknown puzzles the virus imposes to us as medical professionals. Each day we are gaining new information's concerning the clinical expressions and course of the disease that significantly influence the actual therapy we use. Most data we have come from China, Italy, France, and recently the USA and management is guided by the expert opinion. We do not have randomized studies due to recent infection or control groups of patients due to ethical reasons. We learn every day on the virus that forces us to change our health and social directions.

\section{Methods}

The investigators review and summarize the latest and evolving scientific data regarding evidence linking COVID-19 with increased cardiovascular morbidity and mortality. The authors conducted a search of the relevant articles from various databases, namely, PubMed and SCOPUS science, direct for the latest published papers. We also search for expert opinions important for the review paper.

\section{Global burden of COVID-19 pandemic}

COVID-19 is now a global pandemic. Outbreak of pneumonia caused by a new coronavirus occurred in Wuhan in December 2019 and has rapidly spread throughout China and the rest of the world [2], [3]. After virus identification and isolation, the pathogen for this pneumonia was originally called 2019 novel coronavirus (2019-nCoV) but has been officially named severe acute respiratory syndrome coronavirus 2 (SARS-CoV-2) by the World Health Organization (WHO). On January 30,2020 , the WHO declared the outbreak of SARSCoV-2. On February 11, 2020, the WHO announces "COVID-19" as the name of new disease [3], [4]. Before December 2019, the virus was unknown to science. As of April 12, 2020, there were more than 1.846 .983 cases 
worldwide, with nearly 113.885 case-fatalities in a total of 210 countries. Although COVID-19 predominantly affects lung function, it affects the cardiovascular system on multiple levels, increasing morbidity in patients with underlying cardiovascular disease (CVD) and provoking myocardial injury and dysfunction [5]. Patients with established heart disease constitute a particularly challenging group, as many of them have conditions that may be life-threatening if intervention is inadequately delayed. Even with the treatment evidence we have today, those patients have increased risk for complications and unfavorable disease courses.

COVID-19 case fatality rate (CFR, number of deaths/numbers of those diagnosed) is significantly different around the world. The original reports from China are referring a CFR of $2.3 \%$ with lower symptomatic case fatality risk of $1.4 \%$, which is much different from influenza $(0.1 \%)$, Middle East respiratory syndrome (34\%), and SARS (10\%) [6]. Based on reported data from April 12, 2020, the global number of COVID-19 cases is 1.846 .983 , with 113.885 deaths and 421.898 patients recovered. The CFR varies significantly by country: China reported $4.4 \%$ death rate $(82,052$ cases), Italy $8.5 \%$ (156,363 cases), Spain $8.9 \%$ (116,127 cases), Germany $6.9 \%$ (127,57 cases), and the United States $30 \%$ (557,217 cases) [7]. The CFR rises rapidly with increasing age. The CFR is $<1 \%$ for individuals under 50 years of age, rising to $3.6 \%$ for 60 years old and up to $14.8 \%$ for octogenarians. In addition, the CFR increases with disease severity, with CFR of around $50 \%$ among critical patients. Patients with several comorbidities have significantly increased CFR: $10.5 \%$ for CVD; $7.3 \%$ for diabetes mellitus; $6.3 \%$ for chronic obstructive pulmonary disease; $6 \%$ for hypertension; and $5.6 \%$ for patients with cancer [8]. The mortality numbers have region and time differences and are influenced by the volume of testing, the quality of healthcare system, disease treatment, time since initial outbreak, and population characteristics such as age, sex, and population health (Figure 1).

\section{COVID-19 in humans: Virus spread, signs, and symptoms}

The novel COVID-19 virus is a singe-stranded enveloped RNA virus, the seventh so far known human coronavirus (Figure 2). It is assumed to have originated from bats, then moved from bats to an intermediate host and then to humans [9]. Coronaviruses have capacity for rapid mutation and recombination.

COVID-19 is spreading mostly through respiratory droplets but also can be aerosolized or detected in the stool. There is a high viral load in both symptomatic and asymptomatic patients, meaning the asymptomatic spread between person to person is likely, with secondary infection rates ranging up to $5 \%$. The incubation period is believed to be between 2 and 14 days and up to $98 \%$ of individuals will experience symptoms within 11.5 days of exposure [10]. The virus has been demonstrated to remain stable for up to $3 \mathrm{~h}$ in the aerosolized form, up to $24 \mathrm{~h}$ on cardboard and up to $72 \mathrm{~h}$ on plastic or stainless steel. Compared with an outbreak of SARS in 2003, caused by the SARS-CoV, COVID-19 has a stronger transmission capacity [11].

What we currently know is that COVID-19 shows a wide range of manifestations and severity of the disease. Infection usually causes mild upper respiratory infections in younger individuals but may lead to hospitalization in elderly patients with underlying cardiac and lung disease. Initially predominantly affecting older individuals, now we are increasingly facing the spread of the disease among the younger population, with often unpredictable course of the disease, assumed to be caused by the individual immune response to the virus. The most common symptoms are fever (88\%) and dry cough $(67.7 \%)$, as in many other viral syndromes. Rhinorrhea $(4.8 \%)$ and gastrointestinal symptoms (diarrhea 4-14\%, nausea/emesis 5\%) appear to be less frequent with COVID-19. In addition, reported symptoms are loss of smell and taste [12].

Reports we have from China shows that a significant majority of patients $(81 \%)$ had mild symptoms (no pneumonia or mild pneumonia). Among those with more significant symptoms, 14\% experienced severe symptoms and 5\% were critical (respiratory failure, septic shock, and/or multiple organ dysfunction) [12].

\section{COVID-19 and cardiovascular system}

Published data about disease manifestation and progression showed that patients with underlying CVD are among the highest risk individuals for severe disease and death. In a series of 44672 confirmed patients with COVID-19 from China, 14.2\% were reported to have CVD [13]. About $22.7 \%$ of all deaths were in patients with underlying CVD [13]

It is even of a greater concern that COVID-19 can cause cardiac injury in patients without underlying heart condition. Understanding the damage caused by COVID-19 to the cardiovascular system and the underlying mechanisms is of the greatest importance. This will allow timely and effective treatment of patients, meaning reduction of mortality.

A place of attachment of COVID-19 is believed to be angiotensin converting-enzyme 2 (ACE-2), a membrane-linked aminopeptidase and receptor through which the virus can potentially attach to the epithelial cells in the lungs, or to the myocardial cells and mediate tissue injury [14]. The expression level of ACE-2 is probably higher in diabetic and hypertensive individuals, which makes them prone to the infection with COVID-19.

\section{Cardiac injury - elevated cardiac troponin}

The data from published studies showed that patients with myocardial injury (elevated cardiac 
troponin) have higher hospital mortality, up to 3 times [15]. About $50 \%$ of fatal cases have increased high-sensitivity cardiac troponin I during hospitalization, as shown in Table 1 [8]. Troponin elevation goes parallel to the elevation of $\mathrm{N}$-terminal pro-B-type natriuretic peptide and $\mathrm{C}$-reactive protein. It is obvious that troponin rise in the same time with the rise of other inflammatory biomarkers (D-dimer, ferritin, interleukin-6, and lactate dehydrogenase) speaks against isolated myocardial injury mediated through ACE-2. It might be a reflection of cytokine storm or secondary hemophagocytic lymphohistiocytosis.

Temporal changes in troponin levels show slow elevation of values first 2 weeks, and steep elevation $3^{\text {rd }}$ week in patients with a severe and critical form of the disease. During follow-up, the median hs- troponin I among survivors did not change significantly [8].

Cases of ST elevation (STEMI like) without coronary obstruction were published [16], [17] and explained as viral myocarditis or stress cardiomyopathy. However, until now, no signs of direct virus infiltration of the myocardium were published. The scientific data we have point towards inflammation as one of the mechanisms of the multi-organ damage in the course of the COVID-19 disease. Sporadic autopsy cases suggest infiltration of myocardium by interstitial mononuclear inflammatory cells [18].

The use of cardiac magnetic resonance imaging or endomyocardial biopsy may give more answers to these questions.

There is still no evidence of impaired heart function due to myocardial injury in patients who recover from COVID-19. They rather have normal heart function after full recovery. According to that, we may see the myocardial injury and troponin level as a marker of disease severity, related to cytokine storm, hypoxia, vasopressors, and coagulation disturbances. Monitoring and managing a myocardial injury is of utmost importance in severe and critically ill patients [15].

Troponin elevation in the context of COVID-19 infection, in the absence of other signs and symptoms, suggesting acute coronary syndrome, should not a priority lead to invasive diagnostic procedures.

\section{Heart failure}

It is a challenge for every physician to make differential diagnoses between decompensated heart failure, often complicated with pulmonary infection and COVID-19 infection, before laboratory-confirmation. And more than that, chest computed tomography images of patients with decompensated heart failure are very similar to those with infection of COVID-19 [22]. Ground-glass opacity and thickening of interlobular septa are present in both cases, but patients with heart failure have a higher ratio of central versus gradient distribution [22].
Extreme elevations in natriuretic peptides with the cause of death attributed to cardiac failure and arrest are reported in up to $25 \%$ of case-fatality rates [8], [23]. In a large cohort from China, heart failure was reported in $23 \%$ of infected patients and the prevalence was significantly higher among non-survivors (52\% vs. $12 \%$, $p<0.0001$ ) [8].

It is clear that patients with previous heart failure will have a more complicated pulmonary disease of any kind. However, during COVID-19 pandemic, fulminant myocarditis or cardiomyopathy presentations are observed. A hypothesis is proposed that underlying structural heart disease in early-stage (like heart failure with preserved ejection fraction) in the context of pulmonary complications and later in the form of acute systolic heart failure develops as a response to the cytokine phase of COVID-19.

Elderly patients with heart failure may have left ventricular hypertrophy, diastolic dysfunction, or systolic dysfunction. These patients are prone to higher pulmonary vascular pressure in the typical critical care scenario of overload with fluid infusions to maintain blood pressure as well as the administration of parenteral medications. The use of non-steroid anti-inflammatory drugs as well as secretagogues in diabetic patients, alter salt and water balance and may worsen cardiac function.

\section{Coronary artery disease}

Patients with coronary artery disease, stable, or unstable are prone to complications during COVID19 infection, due to coronary plaque rupture or stentthrombosis secondary to pro-coagulant effects of systemic inflammation.

The first autopsy of a 53-year-old woman with chronic renal failure in Jinyintan Hospital showed acute myocardial infarction [8]. About $5.8 \%$ of patients with severe/critical clinical presentation have a history of coronary heart disease, in comparison with $1.8 \%$ of those with non-severe illness [9].

It is important to emphasize that many COVID19 infected patients were presented to the doctor with heart palpitations and chest tightness, instead of fever and cough. Accompanied by ECG changes suggestive of ischemia, represent a trap for the doctors, to reduce cautions toward self-protection. Coronary arteries without coronary obstruction on angiography will raise the first suspicion of infection with COVID-19. However, elevated troponin during COVID-19 infection, if coupled with symptoms and signs of myocardial infarction, should lead to guideline-directed interventions, fibrinolysis, or coronary angioplasty in designated hospitals [24].

\section{Treatment in the light of CVD}

Regarding the treatment of the COVID-19 infection until the beginning of April 2020, more than 
Table 1: Comparison of hs-troponin I levels in severe/critically ill patients and non-critically ill patients

\begin{tabular}{|c|c|c|c|c|}
\hline Authors & No. of pts & Acute cardiac injury (high troponin level) in severe/critical form of disease (ICU pts) & Acute cardiac injury (high troponin level) in non-ICU pts & $p$-value \\
\hline Huang et al. [12] & $41 \mathrm{pts}$ & $31 \%$ & $4 \%$ & $p<0.01$ \\
\hline Wang et al. [19] & $138 \mathrm{pts}$ & $\begin{array}{l}22,2 \% \\
\text { Acute cardiac injury (high troponin level) in fatal cases }\end{array}$ & $\begin{array}{l}2 \% \\
\text { Acute cardiac injury (high troponin level) in survivors }\end{array}$ & $p<0.01$ \\
\hline Zhou et al. [8] & $191 \mathrm{pts}$ & $59 \%$ & $1 \%$ & $p<0.01$ \\
\hline He et al. [20] & 54 pts & $60.9 \%$ & $25.8 \%$ & $p<0.0013$ \\
\hline Shi et al. [21] & $416 \mathrm{pts}$ & $51.2 \%$ & $4.5 \%$ & $p<0.01$ \\
\hline
\end{tabular}

300 clinical trials are ongoing. In the absence of proven effective therapy, supportive care, starting from symptomatic measures, up to complete intensive care support is recommended [25].

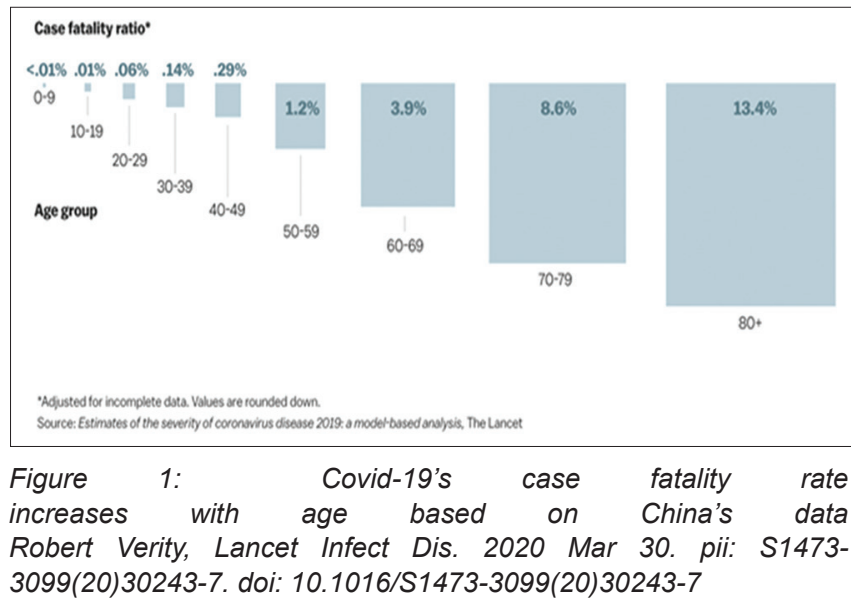

The role of the pharmacologic reninangiotensin-aldosterone blockade, in patients with CVD and COVID-19 infection, needs more research, because the relationship seems to be very complex. Up to date, major health institutions and cardiology societies do not recommend discontinuation of ACE inhibitors or angiotensin II receptor (ARB) medications for all patients taking those medications for another cardiology indication. There is no evidence showing an increased risk of infection or worse clinical course in patients using these medications. However, there are strong warnings that discontinuation of drugs, proven to decrease mortality in patients with CVD,

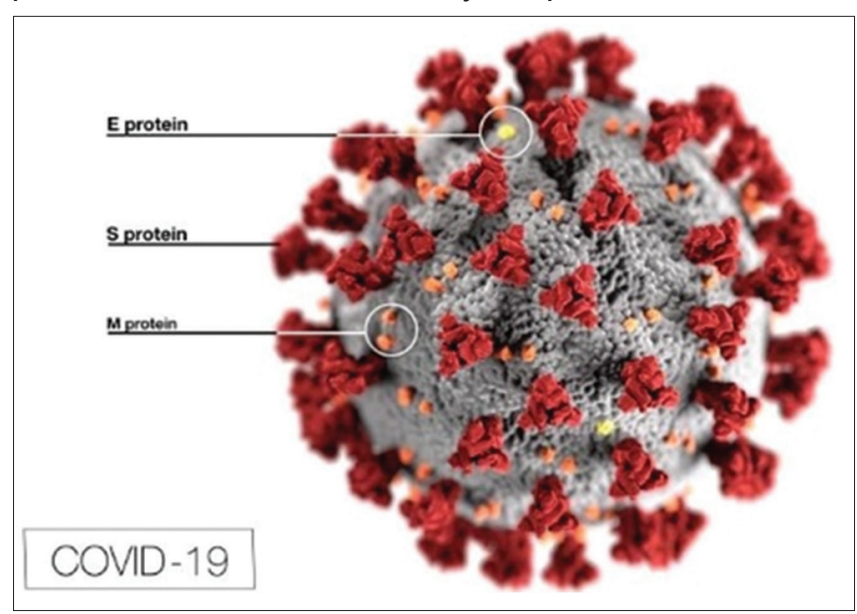

Figure 2: COVID-19 structure https://www.amercrystalassn.org/

may lead to excess mortality due to cardiovascular reasons.

In patients with heart failure, excessive fluid use and drugs that may alter salt and water balance, such as NSAID, should be avoided. Management of advanced heart failure should be guided by the cardiologist, having into consideration the hyperinflammation phase of the infection.

In patients with coronary artery disease and COVID-19 infection, use of plaque stabilizing agents (aspirin, statins, beta-blockers, and angiotensin-converting enzyme inhibitors) has been suggested as a possible therapeutic strategy [26]. Unnecessary diagnostic tests (cardiac troponin and echocardiography) should be minimized, or in some cases, avoided [27], [28], [29]. These tests should be used in the circumstances in which they could add to the management of patients with COVID-19.

Special care should be taken about the potential cardiovascular side-effects of various therapies used for treating the viral infection: Antiretroviral drugs, hydroxychloroquine, azithromycin, etc. Daily electrocardiographic monitoring of the QT interval is suggested [29].

\section{Knowledge gaps and future directions}

The pathobiology, clinical characteristics, and prognosis of the infection are still being studied. An early signal of myocardial injury (cardiac troponin elevation) and new heart failure as a consequence of it is recognized as a bad prognostic marker of the disease. Special caution should be taken in therapeutic management, drug interactions, and proarrhythmogenic potentials in some antiviral protocols.

The current evidence of the association between renin-angiotensin-aldosterone medications and ACE-2 levels with clinical outcome in COVID-19 infection is insufficient. More information needs to be generated.

COVID-19 has emerged as a new disease only a few months ago and it is impossible to discuss the long-term outcome in patients recovering from the infection. There is still no evidence of impaired heart function due to myocardial damage in the acute phase. Follow-up studies and more data are needed to make conclusions.

\section{Conclusion}

Preexisting CVD is common in patients with COVID-19 and those patients are at higher risk of 
morbidity and mortality. Myocardial injury is present in more than $15 \%$ of severely ill patients. Several promising treatments are under investigation, but so far none with the proven clinical efficacy. The continuation of clinically indicated ACEi or ARB therapy is recommended by many heart associations, based on the currently available evidence. We hope the near future will answer the remaining questions and prove the force we make each day to fight the virus.

\section{References}

1. Wu Z, McGoogan JM. Characteristics of and important lessons from the coronavirus disease 2019 (COVID-19) outbreak in China: Summary of a report of 72314 cases from the Chinese center for disease control and prevention. JAMA. 2020;323(13):1239-1242. https://doi.org/10.1001/jama.2020.2648 PMid:32091533

2. Zhou P, Yang XL, Wang XG, Hu B, Zhang L, Zhang W, et al. A pneumonia outbreak associated with a new coronavirus of probable bat origin. Nature. 2020;579(7798):270-3. PMid:32015507

3. Chen N, Zhou M, Dong X, Qu J, Gong F, Han Y, et al. Epidemiological and clinical characteristics of 99 cases of 2019 novel coronavirus pneumonia in Wuhan, China: A descriptive study. Lancet. 2020;395(10223):50713. https://doi.org/10.1016/s0140-6736(20)30211-7 PMid:32007143

4. Andersen KG, Rambaut A, Lipkin WI, Holmes EC, Garry RF. The proximal origin of SARS-CoV-2. Nat Med. 2020;26(4):450-2. https://doi.org/10.1038/s41591-020-0820-9 PMid:32284615

5. Zheng YY, Ma YT, Zhang JY, Xie X. COVID-19 and the cardiovascular system. Nat Rev Cardiol. 2020;17(5):259-60. PMid:32139904

6. Wu JT, Leung $\mathrm{K}$, Bushman $\mathrm{M}$, Kishore $\mathrm{N}$, Niehus $\mathrm{R}$, de Salazar PM, et al. Estimating clinical severity of COVID-19 from the transmission dynamics in Wuhan, China. Nat Med. 2020;26(4):506-10. https://doi.org/10.21203/rs.3.rs-17453/v1 PMid:32284616

7. Coronavirus Disease 2019 (COVID-19): Diagnosis and Management (Narrative Review). Erciyes Med J 2020; 42(3); 1-6.

8. Zhou F, Yu T, Du R. Clinical course and risk factors for mortality of adult inpatients with COVID-19 in Wuhan, China: A retrospective cohort study. Lancet. 2020;395(10229):105462. PMid:32171076 https://doi.org/10.3410/f.737524760.793572448

9. Guan WJ, Ni ZY, Hu Y, Liang WH, Ou CQ, He JX, et al. Clinical characteristics of coronavirus disease 2019 in China. N Engl J Med. 2020;382:1708-20.

10. Lauer SA, Grantz KH, Bi Q, Jones FK, Zheng $Q$, Meredith $\mathrm{HR}$, et al. The incubation period of coronavirus disease 2019 (COVID-19) from publicly reported confirmed cases: Estimation and application. Ann Intern Med. 2020;172(9):577-82. https://doi.org/10.7326/m20-0504 PMid:32150748

11. Van Doremalen N, Bushmaker $T$, Morris $D H$, Holbrook MG, Gamble A, Williamson BN, et al. Aerosol and surface stability of SARS-CoV-2 as compared with SARS-CoV-1. N Engl J Med. 2020;382(16):15647. https://doi.org/10.1101/2020.03.09.20033217

\section{PMid:32182409}

12. Huang $\mathrm{C}$, Wang $\mathrm{Y}$, Li X, Ren L, Zhao J, Hu Y, et al. Clinical features of patients infected with 2019 novel coronavirus in Wuhan, China. Lancet. 2020;395(10223):497-506.

13. Liu Z, Bing X, Zh XZ. Novel coronavirus pneumonia emergency response epidemiology team. The epidemiological characteristics of an outbreak of 2019 novel coronavirus diseases (COVID-19) in China. Zhonghua Liu Xing Bing Xue Za Zhi. 2020;41(2):145-51. PMid:32064853

14. Kuba K, Imai Y, Rao S, Gao H, Guo F, Guan B, et al. A crucial role of angiotensin converting enzyme 2 (ACE2) in SARS coronavirus-induced lung injury. Nat Med. 2005;11(8):875-79. https://doi.org/10.1038/nm1267 PMid: 16007097

15. Han Y. Initial COVID-19 affecting cardiac patients in China. Eur Heart J. 2020;41(18):1719. PMid:32232395

16. Hu H, Ma F, Wei X, Fang Y. Coronavirus fulminant myocarditis saved with glucocorticoid and human immunoglobulin. Eur HeartJ. 2020;2020:1249-50. https://doi.org/10.1093/eurheartj/ehaa190 PMid:32176300

17. Zeng JH, Liu YX, Yuan J, Wang FX, Wu WB, Li JX, et al. First case of COVID-19 infection with fulminant myocarditis complication: Case report and insights. Infection. 2020; 2020:1-5. PMid:32277408

18. Hanley B, Lucas SB, Youd E, Swift B, Osborn M. Autopsy in suspected COVID-19 cases. J Clin Pathol. 2020;73(5):239-42. PMid:32198191

19. Wang D, Hu B, Hu C, Zhu F, Liu X, Zhang J, et al. Clinical characteristics of 138 hospitalized patients with 2019 novel coronavirus-infected pneumonia in Wuhan, China. JAMA. 2020;323(11):1061-9. https://doi.org/10.1001/jama.2020.1585 PMid:32031570

20. He XW, Lai JS, Cheng J, Wang MW, Liu YJ, Xiao ZC, etal Impact of complicated myocardial injury on the clinical outcome of severe or critically ill COVID-19 patients. Zhonghua Xin Xue Guan Bing Za Zhi. 2020;48:E011. PMid:32171190

21. Shi S, Qin M, Shen B, Cai Y, Liu T, Yang F, et al. Association of cardiac injury with mortality in hospitalized patients with COVID19 in Wuhan, China. JAMA Cardiol. 2020;2020:e200950. PMid:32211816

22. Liua KC, Xub P, Lvc WF, Yao JL, Gu JF, Wei W, et al. CT manifestations of coronavirus disease-2019: A retrospective analysis of 73 cases by disease severity. Eur J Radiol. 2020;126:108941. https://doi.org/10.1016/j.ejrad.2020.108941

23. Mehra MR, Ruschitzka F. COVID-19 illness and heart failure: A missing link? JACC Heart Fail. 2020;8(6):512-4. https://doi.org/10.1016/j.jchf.2020.03.004 PMid:32360242

24. Han $\mathrm{Y}$, Zeng $\mathrm{H}$, Jiang $\mathrm{H}$, Yang $\mathrm{Y}$, Yuan $\mathrm{Z}$, Cheng $\mathrm{X}$, et al. CSC expert consensus on principles of clinical management of patients with severe emergent cardiovascular diseases during the COVID-19 epidemic. Circulation. 2020;141(20):e8106. $\quad$ https://doi.org/10.1161/circulationaha.120.047011 PMid:32216640

25. Sanders JM, Monogue ML, Jodlowski TZ, Cutrell JB. Pharmacologic treatmentsforcoronavirusdisease2019(COVID-19):Areview.JAMA 2020;323(18):1824-36. https://doi.org/10.1001/jama.2020.6019 PMid:32282022

26. Xiong TY, Redwood S, Prendergast B, Chen M. Coronaviruses and the cardiovascular system: Acute and long-term implications. Eur Heart J. 2020;41(19):1798800 PMid:32186331 https://doi.org/10.1093/eurheartj/ehaa231

27. ACC Clinical Bulletin Focuses on Cardiac Implications of Coronavirus (COVID-19). Available from: https://www.acc. 
org/latest-in-cardiology/articles/2020/02/13/12/42/acc-clinicalbulletin-focuses-on-cardiac-implications-ofcoronavirus-2019ncov. [Last accessed on 2020 Apr 15].

28. ASE Statement on Protection of Patients and Echocardiography Service Providers During the 2019 Novel Coronavirus Outbreak. Available from: https://www.asecho.org/wp-content/ uploads/2020/03/COVIDStatementFINAL4-1-2020_v2_ website.pdf. [Last accessed on 2020 Apr 15].
29. Ohad O, Kopecky SL, Gluckman TJ, Gersh BJ, Blumenthal RS. Coronavirus Disease 2019 (COVID-19): Epidemiology, Clinical Spectrum and Implications for the Cardiovascular Clinician. Available from: https://www.acc. org/latest-in-cardiology/articles/2020/04/06/11/08/covid-19epidemiology-clinical-spectrum-and-implications-for-thecv-clinician. [Last accessed on $2020 \mathrm{Apr}$ 10]. https://doi. org/10.4103/2543-1463.282193 